\title{
Long-term results of left ventricular reconditioning and anatomic correction for systemic right ventricular dysfunction after atrial switch procedures
}

\author{
Nancy C. Poirier, MDa \\ Jae-Hyeon $\mathrm{Yu}, \mathrm{MD}^{\mathrm{b}}$ \\ Christian P. Brizard, MD ${ }^{\mathrm{b}}$ \\ Roger B. B. Mee, MDC
}

From Ste-Justine Hospital, ${ }^{\mathrm{a}}$ Montreal, Quebec, Canada; Royal Children's Hospital, ${ }^{\text {b }}$ Melbourne, Australia; and Cleveland Clinic Foundation, ${ }^{\mathrm{c}}$ Cleveland, Ohio.

Read at the Eighty-third Annual Meeting of The American Association for Thoracic Surgery, Boston, Mass, May 4-7, 2003.

Received for publication May 13, 2002; revisions received Oct 2, 2003; accepted for publication Oct 6, 2003.

Address for reprints: Roger B. B. Mee, MB, ChB, FRACS, Center for Pediatric and Congenital Heart Disease, Cleveland Clinic Foundation, 9500 Euclid Ave, Unit M41, Cleveland, OH 44195 (E-mail: meer@ ccf.org).

J Thorac Cardiovasc Surg 2004;127:975-81 $0022-5223 / \$ 30.00$

Copyright $\odot 2004$ by The American Association for Thoracic Surgery

doi:10.1016/j.jtcvs.2003.10.024
Objectives: Systemic right ventricular failure after atrial switch procedures for transposition of the great arteries has been addressed at Melbourne's Royal Children's Hospital (1981-1993) and the Cleveland Clinic Foundation (1993-2001) with reconditioning of the morphologically left ventricle by means of pulmonary artery banding followed by an arterial switch operation and an atrial reseptation.

Methods: Thirty-nine patients (Royal Children's Hospital, 19; Cleveland Clinic Foundation, 20) with a median age of 10.8 years (range, 13 months -24 years) entered this protocol a median of 10.3 years (range, $0.5-24$ years) after an atrial switch procedure.

Results: The median duration of pulmonary artery banding was 13 months (range, 0.5-5.4 years). Ten (28\%) patients responded unfavorably to morphologically left ventricular reconditioning (5 mortalities: 4 transplantations and 1 PAB still in place). Twenty-four $(83 \%)$ of the 29 patients who underwent an atrial switch operation and atrial reseptation survived. During a median follow-up period of 8.2 years (range, 1-16 years), 3 patients had cardiac-related deaths. All 18 long-term survivors are asymptomatic. At last echocardiographic evaluation, the morphologically left ventricular function was normal or mildly decreased in 16 (89\%) patients, and all had normal or mildly decreased systemic right ventricular function with no or mild tricuspid regurgitation. Age greater than 12 years was associated with a greater probability of morphologically left ventricular failure and not completing the protocol $(P=.02)$ and a higher operative mortality at anatomic correction $(P=.02)$.

Conclusions: Morphologically left ventricular reconditioning and an anatomic correction protocol should be integrated into a cardiac transplantation program when treating patients with morphologically right ventricular failure after Mustard and Senning procedures. It is an alternative to cardiac transplantation in selected patients, with good long-term results. The response to morphologically left ventricular reconditioning past adolescence is inconsistent.

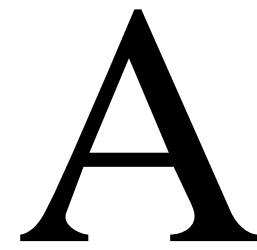

trial switch, namely the Senning and Mustard procedures, was the treatment of choice for transposition of the great arteries (TGA) until the arterial switch operation (ASO) gained acceptance in the 1980s. The major disadvantage of the atrial switch procedures is that the morphologically right ventricle (mRV) remains the systemic ventricle. The systemic right ventricle fails with time and is rated severe in approximately $10 \%$ of patients 10 years after surgical intervention. ${ }^{1,2}$ $\mathrm{mRV}$ failure is a risk factor for late death in this patient population. ${ }^{3,4}$ Many of these patients are currently entering their third decade, and the prevalence of $\mathrm{mRV}$ failure can be expected to increase. 
At the Royal Childrens' Hospital (RCH), a morphologically left ventricle $(\mathrm{mLV})$ retraining and anatomic correction protocol was developed by the senior author and published in $1986 .{ }^{5}$ The protocol reintroduces the $\mathrm{mLV}$ into the systemic circulation and places the $\mathrm{mRV}$ in the pulmonary circuit, alleviating the strain of the systemic circulation on the $\mathrm{mRV}$ and resulting in improved $\mathrm{mRV}$ function and regression of tricuspid regurgitation (TR). Because the $\mathrm{mLV}$ rapidly decreases in mass shortly after birth, it becomes incapable of supporting systemic circulation unless there is persistent pulmonary hypertension or $\mathrm{mLV}$ outflow tract obstruction that mimics the afterload of the systemic circuit. The $\mathrm{mLV}$ is first retrained to maintain systemic pressures by means of pulmonary artery banding (PAB), which increases $\mathrm{mLV}$ afterload. Once the $\mathrm{mLV}$ can provide systemic pressure, an anatomic correction is performed that consists of an atrial baffle takedown, an atrial septum reconstruction, and an ASO. Cardiac transplantation has been integrated into the treatment protocol since 1988. The lack of donor hearts still claiming the lives of $20 \%$ to $30 \%$ of patients on both adult and pediatric transplantation waiting lists and the annual mortality rate of approximately $2.5 \%$ per year during the first 10 years after transplantation ${ }^{6}$ were additional motivations to further perfect this protocol.

Since 1981, at the RCH (1981-1993) and the Cleveland Clinic Foundation (CCF; 1993-2002), a PAB and anatomic correction protocol has been offered to patients with progressive and symptomatic mRV dysfunction. Patients excluded from this protocol and eventual transplantation candidates have irreversible $\mathrm{mLV}$ dysfunction, pulmonary valve abnormalities rendering it unsuitable as a neoaortic valve, $\mathrm{mLV}$ outflow tract obstruction that cannot be adequately relieved, and uncontrolled arrhythmia.

The aim of this work is 4-fold: (1) report our results with this protocol; (2) establish which patients are more likely to respond favorably to $\mathrm{mLV}$ retraining and anatomic correction; (3) define the role of PAB as a sole treatment modality; and (4) determine the place for this protocol in 2002 with the majority of the atrial baffle population now older than 20 years.

\section{Patients and Methods \\ Patients}

A total of 39 patients, 19 from the $\mathrm{RCH}$ and 20 from the CCF, including 20 male and 19 female subjects, entered the $\mathrm{mLV}$ retraining and anatomic correction protocol. The median age at the beginning of the protocol was 10.3 years (range, 0.5-24 years; mean, $10.7 \pm 5.3$ years), with $24(62 \%)$ patients aged less than 12 years and 15 patients (38\%) older than 12 years. The patients were significantly older in the $\mathrm{CCF}$ group ( $\mathrm{RCH}$ median, 9.2 years [range, 0.6-16.1 years); CCF median, 13.9 years [range, 2.1-24 years]; $P=.007)$. Their initial diagnosis was TGA with a ventricular septal defect in $21(54 \%)$ patients, TGA with an intact septum in $12(31 \%)$ patients, and Taussig-Bing in $6(15 \%)$ pa- tients. An atrial switch procedure had been practiced a median of 9 years (range, $0.2-22$ years; mean, $9.7 \pm 5.4$ years) beforehand: a Senning procedure in $22(56 \%)$ patients and a Mustard operation in $17(44 \%)$ patients. The majority $(82 \%)$ of the patients were in New York Heart Association (NYHA) functional class 2, with 7 (18\%) patients in NYHA functional class 3. Twelve (31\%) patients had supraventricular arrhythmias, including 3 with a permanent pacemaker.

Cardiac transplantation began in 1988 at the $\mathrm{RCH}$. Eleven (58\%) of the 19 patients operated on at the $\mathrm{RCH}$ were entered into the $\mathrm{mLV}$ retraining and anatomic correction protocol before the establishment of the cardiac transplantation program. Of the 20 patients treated at the CCF, $4(20 \%)$ were not transplant candidates.

Preprotocol cardiac catheterization was performed in all 39 patients. Four patients (ages 2.2, 10.8, 16.5, and 20 years) with $\mathrm{mLV}$ outflow tract obstruction $(\mathrm{n}=2)$ or pulmonary hypertension caused by atrial baffle obstruction $(\mathrm{n}=2)$ had an $\mathrm{mLV}$ capable of generating systemic pressures (100, 90, 98, and $84 \mathrm{~mm} \mathrm{Hg}$ ), and therefore an anatomic correction was performed without preliminary PAB. All 4 patients had mild or moderate $\mathrm{mRV}$ dysfunction and TR with a normally functioning $\mathrm{mLV}$ and no mitral regurgitation (MR) documented by means of echocardiography.

The remaining $35(90 \%)$ patients had $\mathrm{mLV}$ systolic pressures (mLVPs) that could not sustain systemic pressures with median mLVPs of $34 \mathrm{~mm} \mathrm{Hg}$ (range, 17-65 mm Hg; mean, $36.4 \pm 13 \mathrm{~mm}$ $\mathrm{Hg}$ ) and a median ratio of the $\mathrm{mLV}$ and $\mathrm{mRV}$ systolic pressures of 0.30 (range, 0.18-0.6; mean, $0.35 \pm 0.11$ ). Preprotocol echocardiographic evaluation of these patients showed severe $\mathrm{mRV}$ dysfunction in 9 (26\%) patients, moderate dysfunction in $22(63 \%)$ patients, and mild dysfunction in $4(11 \%)$ patients. Concomitant TR was severe in 13 (37\%) patients and moderate in 17 (48\%) patients. Mild TR with moderate-to-severe mRV dysfunction was observed in $5(14 \%)$ patients. All patients with mild mRV dysfunction had severe TR. Moderate $\mathrm{mLV}$ dysfunction was observed in 1 patient, and mild dysfunction was observed in 2 patients, including one with moderate MR. Fourteen patients evaluated after 1995 underwent pre-PAB cardiac magnetic resonance imaging (MRI). The median $\mathrm{mLV}$ indexed mass was $52.5 \mathrm{~g} / \mathrm{m}^{2}$ (range, $31-105 \mathrm{~g} / \mathrm{m}^{2}$; mean, $55 \pm 19 \mathrm{~g} / \mathrm{m}^{2}$ ), with the normal value being greater than $80 \mathrm{~g} / \mathrm{m}^{2}$.

\section{Protocol}

Details of the treatment protocol and surgical technique, including illustrations, can be found in previous publications. ${ }^{7-9}$ A few important points of the protocol are outlined below.

$\boldsymbol{P A B}$. Invasive monitoring includes a Swan-Ganz catheter in patients heavier than $15 \mathrm{~kg}$ to record $\mathrm{mLV}$ pressures during $\mathrm{PAB}$. It is floated into the $\mathrm{mLV}$, and the balloon is kept inflated and positioned in the middle of the mLV cavity, thus avoiding arrhythmias induced by the catheter. Through a median sternotomy, the band is applied and tightened until the systemic blood pressure decreases and the central venous pressure increases, achieving a 20 - to $50-\mathrm{mm}-\mathrm{Hg} \mathrm{mLV}$ pressure increase. A transesophageal echocardiograph documents the effects of the PAB on $\mathrm{mRV}$ and $\mathrm{mLV}$ size and function, septal position, and tricuspid valve function. A shift in the interventricular septum with an increase in $\mathrm{mLV}$ pressures and reduction of the $\mathrm{TR}$ and $\mathrm{mRV}$ dysfunction are 
sought. A tight band can reduce mLV function, decrease the contractility of the mLV, and induce MR. Dopamine (2.5-5 $\mu \mathrm{g}$. $\left.\mathrm{kg}^{-1} \cdot \min ^{-1}\right)$ or dobutamine $\left(2.5-5 \mu \mathrm{g} \cdot \mathrm{kg}^{-1} \cdot \min ^{-1}\right)$ is started on leaving the operating room and continued for the first 5 days of $\mathrm{mLV}$ retraining. On the first postoperative day, digoxin and diuretics are started, and if the $\mathrm{mLV}$ function remains good on control transthoracic echocardiography (TTE), the patient is extubated. One week after banding, after discontinuation of dopamine, a TTE is repeated, and MRI is used to evaluate ejection fraction and ventricular mass. Myocardial hypertrophy caused by cellular edema identified at T2-weighted MRI analysis is a probable sign of myocardial damage and might result in late scarring and $\mathrm{mLV}$ dysfunction. A cardiac catheterization is also performed before discharge to evaluate ventricular pressures. If there is any evidence of mLV failure, the pulmonary artery band is loosened immediately. If the mLV pressure has decreased since the operation and there is no sign of mLV compromise, the pulmonary artery band is tightened during the same hospitalization.

$\mathrm{mLV}$ function and pressures are assessed every 3 months by means of TTE and by means of cardiac catheterization every 6 months. Before the switch conversion, a TTE, a cardiac catheterization, and MRI are performed to determine whether anatomic correction is feasible. The mLV must function normally, generating greater than $80 \%$ systemic blood pressures and suprasystemic pressures with the administration of isoproterenol. The MRI evaluation, echocardiographic evaluation, or both should show normal ventricular mass and ventricular wall thickness indexed for weight and age. If these criteria are not met, $\mathrm{PAB}$ is repeated. If $\mathrm{mLV}$ dysfunction is observed, PAB is not tolerated, or both, patients are listed for transplantation if they are in end-stage heart failure, have deteriorating functional class, and have a limited life expectancy.

Anatomic correction. Technical details of the arterial switch, Mustard-Senning takedown, and atrial septum reconstruction are illustrated in previous reports. ${ }^{7-9}$

Postoperatively, the mLV function is optimized with aggressive afterload reduction by using phenoxybenzamine $(0.5 \mathrm{mg} / \mathrm{kg}$ every 8 hours), nitroprusside, or both during the immediate postoperative period. Dopamine, dobutamine, milrinone, or a combination of these agents is added to further improve cardiac output. Nitroglycerin $\left(0.5-5.0 \mu \mathrm{g} \cdot \mathrm{kg}^{-1} \cdot \mathrm{min}^{-1}\right)$ is administered to prevent coronary vasospasm. Chronic oral afterload reduction is begun once the patient is extubated. Biventricular function is monitored with serial TTE perioperatively and periodically after discharge.

\section{Statistical Methods}

Clinical and follow-up data were retrieved from medical records. Statistical analysis was obtained with Instat 3.05 software (Graphpad Software, Inc, San Diego, Calif). Early postoperative death was defined as occurring within 30 days of a procedure or during the same hospitalization. The data are reported as a medians, ranges, and means $\pm \mathrm{SD}$.

The significance of continuous variables on early mortality was determined by means of the Mann-Whitney rank sum test. Categoric variables were analyzed with the use of a $\chi^{2}$ test or a Fisher exact 2-tailed test if one of the numerators of the proportion was equal to or less than 5 events.

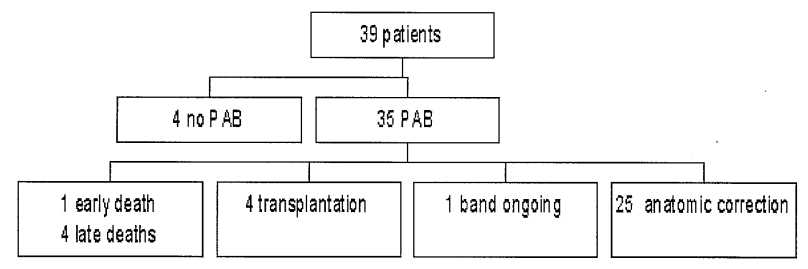

Figure 1. Clinical course after PAB. (Reproduced with permission from Mee RBB. Arterial Switch Operation for RV Failure Following Mustard and Senning Operations. In Stark J, Pacifico A, editors: Reoperations in Cardiac Surgery. Heidelberg: SpringerVerlag; 1989. p 217-32, copyright 1989 by Springer-Verlag.)

\section{Results}

For the 35 patients who underwent $\mathrm{mLV}$ retraining, this was achieved after a median of $2 \mathrm{PAB}$ procedures. A single PAB procedure was required in $15(43 \%)$ patients; however, multiple bandings were necessary in 20 patients (2 PAB procedures, 6 patients; 3 PAB procedures, 8 patients; 4 PAB procedures, 5 patients; 5 PAB procedures, 1 patient). Fifteen $(43 \%)$ patients underwent repeat interventions immediately after initial PAB: 13 were tightened, and 2 were loosened. The median duration of $\mathrm{mLV}$ retraining was 13 months (range, 0.5-65 months; mean, $20.3 \pm 17$ months). Eighteen (51\%) patients improved their mRV function, TR, or both. Function remained unchanged in 15 (43\%) patients and deteriorated in $2(6 \%)$ patients.

The clinical course after PAB is outlined in Figure 1. Early postoperative mortality after PAB was $3 \%$ (1/39). The only early postoperative death was a 6-month-old child with severe TR and mRV dysfunction after a Senning procedure who underwent a PAB with a concomitant tricuspid valve replacement before cardiac transplantation was available in Melbourne in 1988. There were 4 late deaths, 2 of which were also before 1988 and occurred in patients with severe $\mathrm{mRV}$ failure who did not tolerate PAB. Another patient with a significant baffle leak and obstruction was debanded immediately postoperatively because of hemodynamic instability. The family later refused transplantation, and he died 2 months later from progressive mRV dysfunction and TR. Another child died 2 months after PAB of ventricular tachycardia. Cardiac transplantation was performed in 4 patients who presented with mLV dysfunction 2 months to 4 years after PAB. One patient with initial moderate mRV dysfunction and TR has been banded for 5.5 years and remains asymptomatic, with only mild mRV dysfunction and TR in addition to a normally functioning $\mathrm{mLV}$. The remaining 25 (71\%) patients were successfully retrained and presented for ASO and atrial reseptation.

In an attempt to identify patients amenable to $\mathrm{mLV}$ retraining, we examined a number of factors outlined in Table 1. On univariate analysis, the presence of preoperative arrhythmia was the only significant risk factor for failed 
TABLE 1. Univariate predictors of postoperative mortality and $\mathrm{mLV}$ failure leading to transplantation after PAB

\begin{tabular}{|c|c|c|c|}
\hline Variable & $\begin{array}{c}\text { Mortality mLV } \\
\text { failure-Tx } \\
(\mathrm{n}=10)\end{array}$ & $\begin{array}{l}\text { Successful mLV } \\
\text { retraining } \\
(\mathrm{n}=25)\end{array}$ & $P$ value \\
\hline Age (y) & $14.3(0.6-19)$ & $9.7(2.1-24)$ & .58 \\
\hline $\begin{array}{l}\text { No. of PAB } \\
\text { procedures }\end{array}$ & $2(1-4)$ & $2(1-5)$ & .60 \\
\hline Arrhythmia & 7 & 3 & .002 \\
\hline Era (RCH/CCF) & $4 / 6$ & $14 / 11$ & .47 \\
\hline \multicolumn{4}{|c|}{ Cardiac catheterization: Pre-PAB } \\
\hline mLVP (mm Hg) & $36.5(17-65)$ & $30(18-62)$ & .97 \\
\hline $\mathrm{mLVP} / \mathrm{mRVP}$ ratio & $0.33(0.18-0.5)$ & $0.3(0.18-0.6)$ & 1.0 \\
\hline \multicolumn{4}{|c|}{ Echocardiography: Pre-PAB } \\
\hline Severe mRV failure & 4 & 5 & .39 \\
\hline Severe TR & 5 & 8 & .44 \\
\hline \multicolumn{4}{|c|}{ Magnetic resonance imaging: Pre-PAB } \\
\hline $\mathrm{mLV}$ massi $\left(\mathrm{g} / \mathrm{m}^{2}\right)$ & $54(42-65)$ & $59(36-105)$ & .50 \\
\hline
\end{tabular}

Continuous variables are expressed as medians (ranges). $m L V$, Morphologically left ventricle; $T x$, cardiac transplantation; $P A B$, pulmonary artery banding; $R C H$, Royal Children's Hospital; $C C F$, Cleveland Clinic Foundation, $m L V P$, morphologically left ventricular systolic pressure; $m R V P$, morphologically right ventricular systolic pressure; $T R$, tricuspid regurgitation; massi, indexed ventricular mass.

retraining $(P=.002)$. Age, the number or duration of PAB procedures, initial $\mathrm{mLVP}$, and the severity of $\mathrm{mRV}$ failure were not significantly different when comparing data of patients with successful and failed $\mathrm{mLV}$ retraining.

A total of 29 (74\%) of the initial 39 patients underwent ASO and atrial reseptation, including the 4 patients who did not undergo initial PAB (Figure 2). Their median mLVP before anatomic correction was $95 \mathrm{~mm} \mathrm{Hg}$ (range, 60-160 $\mathrm{mm} \mathrm{Hg}$; mean, $96 \pm 24 \mathrm{~mm} \mathrm{Hg}$ ), for a median increase in $\mathrm{mLVP}$ during $\mathrm{mLV}$ retraining of $61 \mathrm{~mm} \mathrm{Hg}$ (range, 12-142 $\mathrm{mm} \mathrm{Hg}$; mean, $61 \pm 31 \mathrm{~mm} \mathrm{Hg}$ ). The median $\mathrm{mLV} / \mathrm{mRV}$ pressure ratio was 0.91 (range, 0.5-1.6; mean, $0.90 \pm 0.35$ ). At echocardiography, mRV function was severely decreased in 5 patients, and 24 had either mild or moderate dysfunction. Only one patient had residual severe TR after retraining. Moderate $\mathrm{mLV}$ function was seen after retraining in 3 patients, and 6 had mild mLV impairment, with mild MR in 4 patients. Nine patients had precorrection MRI studies, with a median $\mathrm{mLV}$ indexed mass of $86 \mathrm{~g} / \mathrm{m}^{2}$ (range, $69-105 \mathrm{~g} / \mathrm{m}^{2}$; mean, $85.8 \pm 12.2 \mathrm{~g} / \mathrm{m}^{2}$ ).

The early operative mortality after ASO and atrial reseptation was $17 \%(5 / 29)$. All 5 patients were either not transplant candidates $(\mathrm{n}=4)$ or transplantation was unavailable $(\mathrm{n}=1)$. Four died of $\mathrm{mLV}$ failure caused by myocardial ischemia. Autopsies were performed in 2 patients and revealed patent coronary arteries but multiple small subendocardial and transmural myocardial infarcts. A young adult died after massive hemoptysis from pulmonary arteriovenous malformations identified at autopsy. One patient had biventricular failure, had a left ventricular assist device implanted on postoperative day 1 , and was transplanted 5 days later.

During a median follow-up period of 8.2 years (range, 1-17 years; mean, $8.3 \pm 4.8$ years), 2 children with progressive biventricular failure were transplanted 1 and 2 years after anatomic correction. There were 3 late deaths, all of progressive $\mathrm{mLV}$ failure. One young adult had refused transplantation, a child died before transplantation was available, and a third patient died 14 months postoperatively of congestive heart failure.

The 18 long-term survivors are doing very well in NYHA functional class 1 or 2 . Thirteen (72\%) patients are in sinus rhythm, a sick sinus syndrome persists in $3(17 \%)$ patients, and isolated premature ventricular beats were observed in $2(11 \%)$ patients. Four patients subsequently had aortic insufficiency, and 2 have undergone aortic valve replacement. Three patients have dilated aortic roots and are followed closely. Follow-up echocardiography revealed the presence of moderate and severe $\mathrm{mLV}$ dysfunction in 2 patients, and the remaining 16 have no or mild mLV dysfunction. MR, TR, and $\mathrm{mRV}$ dysfunction was either absent or mild in all patients.

Of the 4 patients with no prior $\mathrm{mLV}$ retraining, a successful anatomic correction was performed in 2 patients: one patient underwent transplantation after postoperative extracorporeal membrane oxygenation support, and another died after the operation.

Overall, of the 39 patients initially enrolled in this program, there are 29 (74\%) long-term survivors: 18 anatomic correction survivors in NYHA functional class 1 or 2 who were transplant free, 7 patients doing well after transplantation, and 1 patient who is still banded in NYHA functional class 1.

Variables evaluated as potential risk factors for failed anatomic correction (postoperative death, $\mathrm{mLV}$ failure leading to transplantation, or both) after ASO and atrial reseptation are listed in Table 2. Older age significantly increased the probability of failing anatomic correction. The oldest patient to successfully undergo ASO and reseptation and thus complete the protocol was 16.5 years of age. Fifteen (62\%) of the 24 patients younger than 12 years of age at the start of the protocol successfully completed $\mathrm{mLV}$ retraining and anatomic correction, whereas the success rate was significantly less (3/15 [20\%] patients) in patients older than 12 years $(P=.02)$. The presence of arrhythmia before anatomic correction was significantly higher in patients who failed conversion $(P=.02)$. Although the occurrence of coronary pattern other than Yacoub type A or D did not reach significance, 4 of the 5 early deaths after conversion had difficult coronary anatomies (single coronary ostium off of sinus $2, \mathrm{n}=2$; single coronary ostium off of sinus $1, \mathrm{n}$ $=1$; and 1 with multiple coronary ostia, $\mathrm{n}=2$ ). Preconversion mLVPs were significantly higher in the patients 


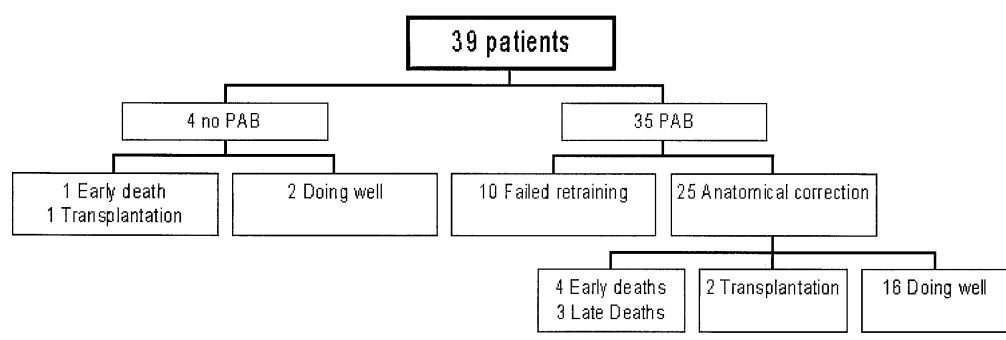

Figure 2. Clinical course after anatomic correction. (Reproduced with permission from Mee RBB. Arterial Switch Operation for RV Failure Following Mustard and Senning Operations. In Stark J, Pacifico A, editors: Reoperations in Cardiac Surgery. Heidelberg: Springer-Verlag; 1989. p 217-32, copyright 1989 by Springer-Verlag.)

who successfully underwent anatomic correction $(P=.03)$; however, there was no definitive mLVP cutoff identified that could reliably predict successful conversion. Furthermore, the presence of severe $\mathrm{mRV}$ dysfunction was associated with a higher failure rate $(P=.05)$, possibly because of an inadequate increase in mLVP and thus a less important shift in the interventricular septum. The type of atrial baffle, concomitant procedures, the era in which the operation was performed, and $\mathrm{mLV}$ indexed mass at MRI were not significantly different between the 2 groups.

\section{Discussion}

The concept of $\mathrm{mLV}$ retraining for $\mathrm{mRV}$ failure after atrial switch procedures was introduced close to 2 decades ago 5 ; however, many aspects of $\mathrm{mLV}$ retraining and anatomic correction have remained elusive, and we attempted to answer these in this work.

It is now well established that the mLV geometry influences that of the $\mathrm{mRV}$, which explains the improvement of the $\mathrm{mRV}$ and $\mathrm{TR}$ with $\mathrm{PAB} .{ }^{9-13}$ As the $\mathrm{mLV}$ pressure increases during retraining, the ventricular septum will shift from a leftward to a midline position, and the mRV enddiastolic and end-systolic volumes will decrease. This improves tricuspid valve leaflet coaptation, decreasing TR. A decrease in TR translates into a reduction in $\mathrm{mRV}$ volume load and improved function.

$\mathrm{PAB}$ can act as a bridge to transplantation or delay listing for transplantation by improving mRV function and TR. It has proved to be safe in our patient population and by other authors. ${ }^{10,13}$ In our cohort there were no early deaths and only one late death caused by ventricular arrhythmia because this protocol was done in conjunction with cardiac transplantation. In our experience PAB can be performed in patients with severe $\mathrm{mRV}$ failure; however, patients with atrial arrhythmias are less likely to respond favorably to $\mathrm{PAB}$. Other factors, namely preprotocol $\mathrm{mLV}$ mass and pressure, do not reliably predict which patients will successfully complete $\mathrm{mLV}$ retraining. Progressive $\mathrm{mLV}$ afterload augmentation is vital because overzealous $\mathrm{PAB}$ can induce $\mathrm{mLV}$ failure. A reliable and adjustable $\mathrm{PAB}$ procedure has
TABLE 2. Univariate predictors of postoperative mortality and $\mathrm{mLV}$ failure leading to transplantation after ASO and atrial reseptation

\begin{tabular}{lccc}
\hline & $\begin{array}{c}\text { Mortality } \mathbf{m L V} \\
\text { failure-Tx } \\
\text { (n= 11) }\end{array}$ & $\begin{array}{c}\text { Successful ASO/ } \\
\text { reseptation } \\
\text { (n = 18) }\end{array}$ & $\boldsymbol{P}$ value \\
\hline Age ASO/reseptation (y) & $14.2(6-25)$ & $11.8(2.2-16.5)$ & .04 \\
Age at PAB & $13(4.8-24)$ & $9.3(2.1-16.5)$ & .05 \\
Arrhythmia & 7 & 3 & .02 \\
Coronary anomaly & 5 & 6 & .70 \\
Senning-Mustard & $8 / 3$ & $9 / 9$ & .30 \\
Concomitant procedures & 6 & 6 & .44 \\
Era (RCH/CCF) & $4 / 7$ & $11 / 7$ & .26 \\
Cardiac catheterization pre-ASO/reseptation & & \\
$\quad$ mLVP (mm Hg) & $72(60-108)$ & $100(60-160)$ & .03 \\
$\quad$ mLVP/mRVP ratio & $0.80(0.60-1.00)$ & $0.92(0.50-1.60)$ & .09 \\
Echocardiography pre-ASO/reseptation & & \\
$\quad$ Severe mRV dysfunction & 4 & 1 & .05 \\
$\quad$ Severe TR & 2 & 6 & .61 \\
Magnetic resonance imaging & & & \\
$\quad$ LV massi (g/m $\left.{ }^{2}\right)$ & $83(76-86)$ & $95(69-105)$ & .42 \\
\hline
\end{tabular}

Continuous variables are expressed as medians (ranges). $m L V$, morphologically left ventricle; $A S O /$ reseptation, arterial switch operation and atrial reseptation; $P A B$, pulmonary artery banding; $R C H$, Royal Children's Hospital; $C C F$, Cleveland Clinic Foundation; $m L V P$, morphologically left ventricular systolic pressure; $m R V P$, morphologically right ventricular systolic pressure; $m R V$, morphologically right ventricle; $T R$, tricuspid regurgitation; massi, indexed ventricular mass; $L V$, left ventricular.

yet to be described and would limit the number of interventions needed to retrain the $\mathrm{mLV}$.

It is clear that the response to $\mathrm{mLV}$ retraining and anatomic conversion is inconsistent in adolescents and adults on the basis of not only our data but also those of other authors. ${ }^{8,10-12}$ Successful $\mathrm{mLV}$ retraining in our series was less frequent in patients older than 12 years of age, although a 16.5-year-old patient is among the long-term survivors of the conversion protocol. This inconsistent response to $\mathrm{mLV}$ retraining in older patients is an important problem because the vast majority of patients undergoing an ASO are now older than 20 years. 
Why is there such variability in $\mathrm{mLV}$ retraining responses? How does age affect mLV retraining? Inadequate myocardial perfusion in the presence of sudden increased cardiac work during PAB and induced myocardial hypertrophy is a probable culprit. In fetuses and immature animals the coronary reserve is normal in the presence of pressure-induced hypertrophy. ${ }^{15-18}$ Adult hearts, however, have less myocardial perfusion reserve with hypertrophy produced by an increase in afterload, resulting in myocardial ischemia with acute stress. ${ }^{19,20}$ Reduced coronary flow reserve is thought to be caused by a decrease in capillary density, ${ }^{21}$ a relative decrease in large-caliber coronary arteries, ${ }^{22}$ and/or obstruction of intramural coronary arteries caused by an increase in extravascular pressures. ${ }^{21}$ Furthermore, coronary anatomy other than Yacoub type A and D, including single, intramural, and multiple coronary ostia, seem to be associated with ischemia-related cardiac failure and death after ASO and atrial reseptation. An acute increase in afterload during retraining in older patients can therefore cause ischemic changes that contribute to $\mathrm{mLV}$ failure. The Birmingham group has performed $\mathrm{mLV}$ biopsies before and after retraining to determine whether there is evidence of ischemic damage or fibrosis of the $\mathrm{mLV}$, opting for transplantation if fibrosis was present. ${ }^{22} \mathrm{We}$ have instead used T2-weighted MRI to locate myocardial edema caused by ischemia after $\mathrm{PAB}$, which we believe is the precursor to fibrosis. An MRI is performed 1 week after PAB. If myocardial edema is identified and if there is evidence of $\mathrm{LV}$ dysfunction, the pulmonary artery band is loosened immediately. We are in the process of trying to correlate MRI findings with histology of explanted hearts and autopsy findings to validate this imaging tool.

On the basis of our data, the mLV retraining protocol can be offered as part of a 2-tiered treatment program with cardiac transplantation. ASO and atrial reseptation should be reserved for those with no identified risk factors, particularly adolescents and young adults. In addition to patients with coronary anomalies and signs of myocardial ischemia, patients with mLVPs that are less than systemic and atrial arrhythmias are not candidates for anatomic correction. Atrial arrhythmias have, however, been addressed at anatomic correction with cryoablation techniques, with some success in 2 patients in a recent publication by Mavroudis and Backer. ${ }^{10}$

The small number of patients in our study precludes statistical analysis of the relative contributions of the anatomic variants and hemodynamic parameters on the response to the various steps of the protocol. All but one patient in this study was cared for by the senior author in both institutions, therefore limiting interhospital variation.

In conclusion, the age of patients undergoing Mustard and Senning procedures who present with $\mathrm{mRV}$ failure will be increasing, as seen in our cohort, with the patient popu- lation at the RCH being younger (median, 9.2 years; range, 0.6-16.1 years) in comparison with the more recent patients treated at the CCF (median, 13.9 years; range, 2.1-24 years; $P=.007)$. The prevalence of $\mathrm{mRV}$ failure will probably increase as more and more patients reach their third decade. $\mathrm{mLV}$ reconditioning and anatomic correction is an alternative to cardiac transplantation in selected patients, with good long-term results.

The response to $\mathrm{mLV}$ reconditioning past adolescence is inconsistent. Although anecdotal reports of successful ASO and reseptation have been reported in adults, on the basis of our data, this should be done on a highly selected basis. A clear cutoff age was not identified in our study. The presence of complex coronary anatomy, severe mRV failure, and supraventricular arrhythmias are associated with a decreased conversion rate, decreased survival, or both, and thus transplantation, as a primary treatment modality, should be considered in these patients.

$\mathrm{PAB}$, as a sole treatment modality, can improve $\mathrm{mRV}$ function and reduce TR, thus acting as a bridge to transplantation.

The results of ASO and reseptation and other conventional therapies, including cardiac transplantation, are imperfect, and other therapeutic modalities need to be developed. Adjuncts that stimulate mLV hypertrophy (ie, genetic modulation or myocyte transplantation) and angiogenesis (ie, angiogenic growth factors) are now being developed and will possibly improve the retraining response.

\section{References}

1. Williams WG, Trusler GA, Kirklin JW, et al. Early and late results for a protocol for simple transposition leading to an atrial switch (Mustard) repair. J Thorac Cardiovasc Surg. 1988;95:717-26.

2. Turina MI, Siebenmann R, von Segesser L, Schonbeck M, Senning A. Late functional deterioration after atrial correction for transposition. Circulation 1989;80:I162-7.

3. Gelatt M, Hamilton RM, McCrindle BW, et al. Arrhythmia and mortality after the Mustard procedure: a 30-year single-center experience. J Am Coll Cardiol. 1997;29:194-201.

4. Kirjavainen M, Happonen J-M, Louhimo I. Late results of Senning operation. J Thorac Cardiovasc Surg. 1999;117:488-95.

5. Mee RBB. Severe right ventricular failure after Mustard or Senning operations. Two stage repair: pulmonary artery banding and switch. J Thorac Cardiovasc Surg. 1986;92:385-90.

6. Boucek MM, Novick RJ, Bennett LE, Fiol B, Keck BM, Hosenpud JD. The registry of the International Society of Heart and Lung Transplantation: Second Official Pediatric Report-1998. J Heart Lung Transplant. 1998;17:1141-60.

7. Mee RBB. Arterial switch or right ventricular failure following Mustard or Senning operations. In: Stark J, Pacifico A, ed. Reoperations in cardiac surgery. Heidelburg: Springer; 1989. p. 217-32.

8. Cochrane AD, Karl TR, Mee RBB. Staged conversion to arterial switch for late failure of the systemic right ventricle. Ann Thorac Surg. 1993;56:854-61.

9. Poirier NC, Mee RBB. Left ventricular reconditioning and anatomical correction for systemic right ventricular dysfunction. Semin Thorac Cardiovasc Surg. 2000;3:198-215.

10. Mavroudis C, Backer C. Arterial switch after failed atrial baffle procedures for transposition of the great arteries. Ann Thorac Surg. 2000;69:851-7. 
11. Palalino MA, Stellin G, Brawn WJ, et al. Arterial switch operation after left ventricular retraining in the adult. Ann Thorac Surg. 2000; 70:1753-7.

12. Di Donato RM, Fuji AM, Jonas RA, Casteneda AR. Age-dependent ventricular response to pressure overload. Consideration for the arterial switch operation. J Thorac Cardiovasc Surg. 1992;104:713-22.

13. Van Son JAM, Reddy VM, Silvermann NH, Hanley F. Regression of tricuspid regurgitation after two-stage arterial switch operation for failing systemic ventricle after atrial inversion operation. $J$ Thorac Cardiovasc Surg. 1996;111:342-7.

14. Zak R. Cell proliferation during cardiac growth. Am J Cardiol. 1973; 31:211-9.

15. Olivetti G, Anversa P, Loud AV. Morphometric study of early postnatal development in the left and right ventricular myocardium of the rat. II. Tissue composition, capillary growth and sarcoplasmic alterations. Circ Res. 1980;46:503-12.

16. Anversa P, Olivetti G, Loud AV. Morphometric study of early postnatal development in the right and left ventricular myocardium of the rat. I. Hypertrophy, hyperplasia, and binucleation of myocytes. Circ Res. 1980;46:495-502.

17. Manohar M, Thurmon JC, Tranquilli WJ. Regional myocardial blood flow and coronary vascular reserve in unanesthetized young calves with severe concentric right ventricular hypertrophy. Circ Res. 1981; 48:785-96.

18. Marcus ML, Harrison DG, Chilian WM, et al. Alterations in the coronary circulation in hypertrophied ventricles. Circulation. 1987; 75(suppl I):I19-24.

19. Hoffman JIE, Buckberg GD. The myocardial supply: demand ratio: a critical review. Am J Cardiol. 1978;41:327-32.

20. Tomanek RJ, Palmer PJ, Pieffer GW, Schrieber K, Eastham CL, Marcus ML. Morphometry of canine coronary arteries, arterioles and capillaries during hypertension and left ventricular hypertrophy. Circ Res. 1986;58:38-43.

21. Tomanek RJ, Wangler RD, Bauer CA. Prevention of coronary vasodilation reserve decrement in spontaneously hypertensive rats. Hypertension. 1985;7:533-40.

22. De Giovanni JV. Left ventricular retraining in preparation for a late arterial switch in patients with a failing atrial repair for transposition. In: Proceedings of the International Workshop on Left Ventricular Retraining. Bergamo, Italy: International Heart School; 1996. p. 95105 .

\section{Discussion}

Dr Constantine Mavroudis (Chicago, Ill). Drs Poirier and Mee and their colleagues have presented their cumulative experience with left ventricular retraining for the purpose of converting transposition patients with failed atrial baffle operations to arterial switch. The idea, of course, is to resuscitate the left ventricle as the systemic pumping chamber, resulting in long-term benefit and survival. Notably, this is the largest existing clinical experience with this operative paradigm. Roger Mee and his group have pioneered this approach and now present an analysis with enough patients to perform meaningful comparisons and trends. Congratulations, Dr Poirier, on a beautiful and excellent presentation.

Our experience with this approach is limited to 11 patients, and it mirrors the outcomes that have been presented today. We also found that atrial arrhythmias have been troubling. Because of this, we performed concomitant atrial arrhythmia surgery in 2 patients, which resulted in arrhythmia ablation in both. One patient did well, and the other died from left ventricular failure caused by unrecognized poor left ventricular preparation. We did not believe that the small addition of the atrial arrhythmia surgery participated in the death of this patient. Did you consider adding arrhythmia surgery to your protocol, which might address this formidable issue that you have raised?

In your article you mentioned that the Birmingham group in the United Kingdom has instituted left ventricular biopsies at the time of PAB to help them decide between transplantation and arterial switch. What do you believe is the efficacy of this procedure, and are you planning to institute this in your program?

This is a significant contribution. I would like to congratulate the authors, and I would like to thank the Association for the privilege of discussing this article.

Dr Poirier. Thank you, Dr Mavroudis, for your pertinent questions. Our study has shown that the patients with atrial arrhythmias were less likely to successfully complete the retraining protocol and thus less likely to undergo anatomic correction. Anatomic correction, particularly in the older patients, has a high operative risk and is technically challenging. The additional procedure should probably be avoided. We believe that patients with atrial arrhythmia are probably best served with transplantation.

Myocardial biopsies are an interesting tool and can potentially identify which patients respond favorably to $\mathrm{mLV}$ retraining and are more likely to tolerate anatomic correction. We have instead used T2-weighted MRI to locate myocardial edema caused by ischemia after $\mathrm{PAB}$, which we believe is the precursor to fibrosis. An MRI is performed 1 week after PAB. If myocardial edema is identified, and if there is evidence of LV dysfunction, the pulmonary artery band is loosened immediately. We are in the process of trying to correlate MRI findings with histology of explanted hearts and autopsy findings to validate this imaging tool.

Dr Charles D. Fraser (Houston, Tex). We have had limited experience with this population of patients as well. The one problem that we have struggled with is the dilation of the pulmonary artery, which will become the neoaorta during the period of banding, and I wonder if you could offer some specific tricks on how to deal with that.

Dr Poirier. There are 3 long-term survivors in our cohort of patients who had a dilated neoaorta. Other authors, including Dr Mavroudis, have also reported this. Subjecting the neoaorta to high pressures during PAB might play a part in this dilation; however, dilation does not appear in all patients who have undergone initial left ventricular retraining. We did notice that patients who required a pulmonary valve repair at anatomic correction were more likely to dilate. Possibly medial necrosis plays a part in this dilation, as in other congenital anomalies. We have yet to come up with any tricks to avoid this complication. 